\title{
Diabetes, cardiovascular disease, and chronic kidney disease in South Asia: current status and future directions
}

\author{
South Asians are more susceptible to diabetes and cardiovascular diseases and have worse \\ outcomes than other ethnicities, say Anoop Misra, Tazeen Jafar, and colleagues. They \\ call for urgent action to provide screening and treatment, complemented by population level \\ lifestyle modifications.
}

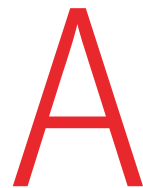

ll South Asian countries have adopted the World Health Organization's Global Action Plan for the Prevention and Control of Non-Communicable Diseases, which recommends a $25 \%$ relative reduction in the prevalence of raised blood pressure by 2025 and a halt to the rise in diabetes and obesity. Although considerable diversity exists between countries, all South Asians have markedly elevated risks of diabetes and variably elevated risks of cardiovascular disease compared with other ethnicities. ${ }^{12}$ In this paper, we review the burden of diabetes, cardiovascular disease, and chronic kidney disease in the region and policies to mitigate this burden. We identify key actions for health authorities and governments to attenuate the rise in non-communicable diseases and meaningfully improve outcomes for the millions of people with, or expected to develop, these diseases.

\section{Methods}

We gathered data on characteristics of populations and health systems from publicly available World Bank reports and WHO's country profiles. Information on death and disability from cardiovascular disease, diabetes, and chronic kidney disease and their attributable risk factors came from Health Metrics and Evaluation's data visualisation

\section{KEY MESSAGES}

South Asians are more likely than other ethnicities to develop diabetes, cardiovascular disease, and chronic kidney disease, and these often have an earlier onset and poor outcomes

Strategies for early diagnosis and treatment including awareness generation, opportunistic screening, availability of low cost drugs, and task shifting to health workers must be prioritised

Countries must consider taxation on unhealthy foods, restrictions on

advertising, and appropriate food labelling tool of the Global Burden of Disease Study 2015. We searched PubMed and Google scholar for relevant literature up to January 2017, using the terms "South Asians", "diabetes", "cardiovascular disease", "myocardial infarction", "stroke", "renal", and "kidney disease". We formulated this paper by drawing from our collective experience in this field and the available literature.

\section{Current epidemiology and trends}

Cardiovascular disease, diabetes, and chronic kidney disease now account for $27 \%, 4.0 \%$, and $3.0 \%$ of deaths, respectively, in South Asia (table 1). ${ }^{3-6}$ Notwithstanding the limited quality and breadth of data, ischaemic heart disease is the leading cause of death in India, Pakistan, Nepal, and Sri Lanka, and stroke is the leading cause in Bangladesh.

The age standardised years of life lost as a result of cardiovascular disease has increased in South Asia in contrast to most other regions, where the reverse is true. ${ }^{5}$ In part, this is because cardiovascular disease events are more common in South Asia than in high income countries. ${ }^{78}$ Furthermore, acute myocardial infarction occurs six years earlier in South Asians than in European counterparts, probably owing to earlier onset of risk factors. Case fatality rates are higher in South Asia, especially in younger adults, thereby increasing the years of life lost. ${ }^{78}$ Stroke and chronic kidney disease may also occur earlier in South Asians. ${ }^{9-11}$ The effect of lives lost due to premature cardiovascular disease is far worse in South Asia than elsewhere, as more than half of the population lives in conditions of poverty. ${ }^{3}$

\section{Susceptibility to diabetes, cardiovascular diseases, and chronic kidney disease} The region has experienced rapid demographic, epidemiological, environmental, and economic transitions. These, coupled with unhealthy lifestyles of physical inactivity and consumption of a calorie dense diet, have increased the risk of non-communicable diseases. In addition, social disparities, wealth inequalities, and conflicts in the region contribute to high rates of stress associated behaviours including smoking. ${ }^{112}$ Evidence from multi-country case-control studies indicates that hypertension, dyslipidaemia, smoking, obesity, diabetes, physical inactivity, low fruit and vegetable intake, and psychosocial stress attribute up to $90 \%$ of the population risk of cardiovascular disease in South Asians. ${ }^{1314}$ Age standardised blood pressure and cholesterol levels and prevalence of diabetes have increased in South Asia over the past decades. ${ }^{15-17}$ High blood pressure and high blood glucose are the leading attributable risk factors for deaths from chronic kidney disease in every South Asian country (table 2).

Adverse metabolic factors are evident in South Asians at an early age. South Asian children have been shown to have adverse metabolic factors (hyperinsulinaemia, dyslipidaemia) compared with British children of similar age and body mass index and higher blood pressure than white children in the US. ${ }^{1819}$ Physical inactivity, dietary imbalances, and increasing obesity amplify this (fig 1). ${ }^{2021}$

South Asian adults have greater risks of cardiovascular disease and diabetes, both of which tend to manifest around 5-10 years earlier than in white Europeans. ${ }^{10}$ The risk of cardiovascular disease is independent of that predicted by established risk factors. Possible mechanisms, among others, include an atherogenic dyslipidaemia driven by high concentrations of triglycerides and low concentrations of high density lipoprotein cholesterol, a pro-coagulant tendency, and higher concentrations of inflammatory cytokines. ${ }^{22}$ Further work is needed to define mechanisms for this excess cardiovascular disease risk. The risk factors vary by socioeconomic strata, geographical region, and migration.

Of particular importance, South Asian adults are more insulin resistant at any given body mass index and may experience more 


\begin{tabular}{|c|c|c|c|c|c|}
\hline & Bangladesh & India & Nepal & Pakistan & Sri Lanka \\
\hline \multicolumn{6}{|l|}{ Population characteristics ${ }^{34}$} \\
\hline Population (millions) & 161.9 & 1311.0 & 28.5 & 189.0 & 21.0 \\
\hline Rural population, \% & 65.7 & 67.3 & 81.4 & 61.2 & 81.6 \\
\hline Life expectancy at birth, years & 71.6 & 68 & 69.6 & 66.2 & 74.8 \\
\hline Population living on $<\$ 3.10 /$ day PPP, $\%$ & NA & 58.1 & 48.3 & 45.0 & 14.0 \\
\hline Overweight/obese (BMI $\geq 25 ; \geq 18$ years), age standardised $\%$ & 18.1 & 22.0 & 18.0 & 23.0 & 25.2 \\
\hline Hypertension ( $\geq 18$ years), age standardised $\%$ & 25.7 & 25.4 & 26.4 & 26.6 & 21.2 \\
\hline Diabetes, age standardised \% & 9.2 & 8.3 & 9.5 & 12.1 & 7.6 \\
\hline \multicolumn{6}{|l|}{ Age standardised CVD and diabetes death rates ${ }^{5}$} \\
\hline CVD death rate per 100000 & 363.9 & 352.6 & 295.2 & 530.9 & 239.9 \\
\hline CVD death rate, $\%$ of total deaths & 36.5 & 30.4 & 29.6 & 44 & 38.0 \\
\hline Ischaemic heart disease, \% of all deaths in 2015 & 15.9 & 17.6 & 17.4 & 28.4 & 20.8 \\
\hline Stroke, \% of all deaths in 2015 & 18.3 & 8.9 & 8.8 & 11.6 & 12.8 \\
\hline Diabetes death rate per 100000 in 2015 & 67.1 & 43.3 & 35.7 & 53 & 50.9 \\
\hline
\end{tabular}

$\mathrm{BMI}=$ body mass index; $\mathrm{CVD}=$ cardiovascular disease; $\mathrm{PPP}=$ purchasing power parity.

Table 2 | Age standardised deaths from chronic kidney disease (CKD) and major attributable risk factors in South $\mathrm{Asia}^{3}$

\begin{tabular}{llllll} 
& Bangladesh & India & Pakistan & Nepal & Sri Lanka \\
\hline Age standardised CKD death rate & & & & & \\
\hline Rate per 100000 & 21.78 & 38.87 & 18.66 & 24.27 & 22.54 \\
\hline $\begin{array}{l}\text { \% of total deaths } \\
\text { Risk factor attributions for CKD }\end{array}$ & 2.2 & 3.4 & 1.6 & 2.4 & 3.6 \\
\hline Systolic blood pressure, \% & 67.4 & 69.4 & 70.5 & 73.9 & 83.1 \\
\hline Fasting blood glucose, \% & 54.4 & 59.4 & 56.1 & 54.5 & 47.8 \\
\hline High body mass index, \% & 11.0 & 14.5 & 23.7 & 16.6 & 18.6 \\
\hline
\end{tabular}

Life course considerations
Maternal nutrition $\rightarrow$ calorie dense child diet/physical inactivity $\rightarrow$ rural-urban migration $\rightarrow$ adverse lifestyles

Fetal growth retardation
Lower birth weights
Less lean mass and
greater fat mass
lifelong
Insulin resistance
phenotype
Potentially less $\beta$ cells
capacity

Poverty

Social class/caste

Female emancipation

Education

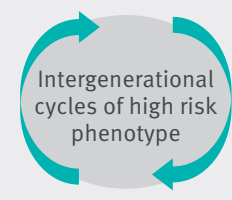

Weight gain, raised blood pressure, lower activity levels, insulin resistance

Social, political, and healthcare considerations Rural develpoment Public health Built environment Food and taxation policies Maternal child health Targeted screening
4 diabetes and at lower body mass indexes $\uparrow$ cardiovascular disease at younger ages chronic kidney disease at younger ages

$\downarrow$ access blood pressure and cholesterol drugs Mass campaigns Access to healthcare

Fig 1 Interacting risk pathways contributing to higher risks of diabetes and cardiovascular disease (CVD) in South Asians, acting over the life course. This begins with poor maternal nutrition and adverse programming, with neonates born at lower average birth weights yet higher fat to lean mass ratios compared with white children. This phenotype worsens over time, with greater weight gain and lower activity levels in South Asian children and adults, leading, in turn, via greater insulin resistance and CVD risk factors, to higher rates of diabetes and CVD, respectively. The parallel societal, political, and health considerations, as well as life course considerations, are also shown. $\mathrm{BMI}=$ body mass index; $\mathrm{BP}=$ blood pressure; $\mathrm{CKD}=$ chronic kidney disease

rapid $\beta$ cell failure. ${ }^{2}$ They may progress more rapidly from a state of high risk of diabetes to frank diabetes and may have accelerated microvascular damage, with evidence of earlier diabetic nephropathy and retinopathy. ${ }^{2}$

\section{Effects of poor and inconsistent treatment}

Significant treatment gaps exist in South Asian populations. Studies report that less than half of all people with hypertension have received a diagnosis or treatment and less than a third have their blood pressure controlled with drugs. ${ }^{23-25}$ The rates of diabetes awareness (50\%), glycaemic control $(<30 \%)$, and chronic kidney disease awareness $(<15 \%)$ are suboptimal. ${ }^{4-28}$

Delay or prevention of diabetes in South Asians will require earlier intervention-that is, at lower levels of glycaemia. This requires wider testing and earlier use of antihyperglycaemic treatment, complemented with population-wide strategies to drive change in dietary habits and physical activity. Although antihypertensive, antidiabetic, and lipid lowering drugs are part of WHO's list of essential medicines, availability in government primary care facilities is poor and patients must often pay out of pocket for these drugs. Social insurance schemes in countries are not available to the majority of the population, ${ }^{29} 30$ and they tend to cover hospital based treatment and do not provide for standardised screening and medical management of these conditions in primary care.

Under-diagnosis and under-treatment result in higher rates of myocardial infarction and stroke, with adverse outcomes due to poor access to standardised and affordable treatment. Most patients with acute ischaemic heart disease are brought to the hospital too late to qualify for reperfusion therapy. ${ }^{31}$ Management in primary care is less than satisfactory, and many patients do not receive appropriate drugs owing to gaps in the knowledge and practices of healthcare providers. ${ }^{32-34}$ The situation is much worse in rural areas, where an acute event is more likely to be fatal. ${ }^{3135}$

\section{Health policies are not geared to respond to the rising challenge}

Non-communicable diseases have been a recent addition to the policy agenda in all South Asian countries. Public health expenditure varies across countries, but overall investment is insufficient to support services for the prevention and management of cardiovascular disease, diabetes, and chronic kidney disease (table 3). ${ }^{36}$ Implementation has been slow owing to donor agencies having limited interest in investing in non-communicable diseases and lack of engagement between governments and professional organisations in this field. 


\begin{tabular}{|c|c|c|c|c|c|}
\hline & Bangladesh & India & Nepal & Pakistan & Sri Lanka \\
\hline \multicolumn{6}{|l|}{ Healthcare system } \\
\hline $\begin{array}{l}\text { Health expenditure per capita PPP, } \\
\text { \$Int }\end{array}$ & 88.1 & 267.4 & 137.4 & 129 & 369.2 \\
\hline Health expenditure as \% of GDP & 2.8 & 4.7 & 5.8 & 2.6 & 3.5 \\
\hline \multicolumn{6}{|c|}{ NCDs in local healthcare infrastructure ${ }^{4}$} \\
\hline $\begin{array}{l}\text { Surveillance and monitoring of NCDs } \\
\text { or risk factors }\end{array}$ & $\begin{array}{l}\text { Mostly ad hoc sub- } \\
\text { national surveys; } \\
\text { nationally representative } \\
\text { surveillance conducted in } \\
2011 \text { (none since then) }\end{array}$ & $\begin{array}{l}\text { Mostly ad hoc } \\
\text { sub-national surveys }\end{array}$ & $\begin{array}{l}\text { Nationally } \\
\text { representative } \\
\text { surveillance } \\
\text { conducted in 2013; } \\
\text { no serial monitoring }\end{array}$ & $\begin{array}{l}\text { Mostly ad hoc } \\
\text { sub-national surveys; } \\
\text { nationally representative } \\
\text { surveillance conducted } \\
\text { during 1990-94 (none } \\
\text { since then) }\end{array}$ & $\begin{array}{l}\text { Mostly ad hoc } \\
\text { sub-national surveys }\end{array}$ \\
\hline $\begin{array}{l}\text { NCD unit or department. in Ministry } \\
\text { of Health (as of 2013) }\end{array}$ & Yes & Yes & Not known & $\begin{array}{l}\text { Yes (tobacco control unit } \\
\text { only) }\end{array}$ & Yes \\
\hline $\begin{array}{l}\text { Existence of operational policy/ } \\
\text { strategy/action plan for CVD (as of } \\
\text { 2013) }\end{array}$ & Yes & Yes & No & No & Yes \\
\hline National/provincial NCD policy & $\begin{array}{l}\text { National Communication } \\
\text { and Action Plan for } \\
\text { reducing NCD high risk } \\
\text { behaviours 2014-16 }\end{array}$ & $\begin{array}{l}\text { National Programme For } \\
\text { Prevention and Control } \\
\text { of Cancer, Diabetes, } \\
\text { Cardiovascular Disease } \\
\text { and Stroke }\end{array}$ & $\begin{array}{l}\text { Multi-sectoral Action } \\
\text { Plan for the } \\
\text { Prevention and } \\
\text { Control of } \\
\text { Non-Communicable } \\
\text { Diseases (2014-20) }\end{array}$ & $\begin{array}{l}\text { National Action Plan for } \\
\text { Prevention and Control } \\
\text { of Non-Communicable } \\
\text { Diseases and Health } \\
\text { Promotion in Pakistan } \\
2004\end{array}$ & $\begin{array}{l}\text { National policy and } \\
\text { strategic framework } \\
\text { for prevention and } \\
\text { control of chronic } \\
\text { non-communicable } \\
\text { diseases } 2009\end{array}$ \\
\hline $\begin{array}{l}\text { Local hypertension treatment } \\
\text { guidelines }\end{array}$ & No local guidelines & $\begin{array}{l}2013 \text { Indian guidelines } \\
\text { on hypertension by the } \\
\text { Association of Physicians } \\
\text { of India }\end{array}$ & No local guidelines & $\begin{array}{l}\text { Pakistan Hypertension } \\
\text { League } 1998\end{array}$ & $\begin{array}{l}\text { Health Sector } \\
\text { Development Project } \\
2007\end{array}$ \\
\hline $\begin{array}{l}\text { Local diabetes management } \\
\text { guidelines }\end{array}$ & $\begin{array}{l}\text { Guidelines for care of type } \\
2 \text { diabetes in Bangladesh } \\
2003\end{array}$ & $\begin{array}{l}\text { Indian Council of Medical } \\
\text { Research guidelines for } \\
\text { management of type } 2 \\
\text { diabetes, } 2005\end{array}$ & No local guidelines & No local guidelines & $\begin{array}{l}\text { Ministry of Sri Lanka } \\
\text { diabetes management } \\
\text { guidelines, } 2011\end{array}$ \\
\hline NCD as line item in health budget & \multicolumn{4}{|c|}{ Not as main line item; however, recent addition in other programme categories } & $\begin{array}{l}\text { Yes, as main line item } \\
\text { since } 2011\end{array}$ \\
\hline
\end{tabular}

$\mathrm{CVD}=$ cardiovascular disease; $\mathrm{GDP}=$ gross domestic product; $\mathrm{NCD}=$ non-communicable diseases; $\mathrm{PPP}=$ purchasing power parity.

In India, the National Programme for Prevention and Control of Cancer, Diabetes, CVD and Stroke has piloted opportunistic screening of risk factors for non-communicable diseases for people over 30 years of age. Furthermore, as part of the national health mission, the Indian government has outlined an operational plan for universal screening for hypertension and diabetes. ${ }^{31}$ A model of opportunistic screening for diabetes in patients with tuberculosis is being evaluated in Sri Lanka. ${ }^{37}$ Examples of successful public-private partnerships for non-communicable disease healthcare in the region are limited. Pakistan's National Action Plan for Non-communicable Diseases is one such model, ${ }^{38}$ which involved a tripartite collaboration with Heartfile, a not for profit organisation, in formulation of policy and implementation in partnership with the government and WHO.

\section{Recommendations}

Progress towards the targeted reductions in death and disability from cardiovascular disease, diabetes, and chronic kidney disease would not be possible without concerted, multi-sectoral efforts by various government entities and non-government partners. We recommend the following essential policy and health system interventions.

Implementation of taxes on unhealthy foods A tax of $20 \%$ on sugar sweetened drinks in India is projected to reduce the prevalence of overweight and obesity by 3.0\% (95\% confidence interval $1.6 \%$ to $5.9 \%$ ) and the incidence of type 2 diabetes by $1.6 \%$ (1.2\% to $1.9 \%$ ) over the period 2014-23, assuming that consumption increases in line with current trends. ${ }^{39}$ In Mexico, an excise tax of $10 \%$ on sugar sweetened drinks decreased consumption by an average of $6 \%$ over one year. ${ }^{40}$ The Indian state of Kerala recently announced a "fat tax" on pizzas, burgers, sandwiches, and tacos sold through branded food outlets. ${ }^{41}$ Such strategies must be adopted in cities of South Asia that experience widespread marketing and consumption of unhealthy fast foods.

Furthermore, a $20 \%$ tax on palm oil purchases in India is projected to avert approximately 363000 (95\% confidence interval 247000 to 479000 ) deaths from myocardial infarctions and strokes over the period 2014-23 (1.3\% reduction in cardiovascular deaths). ${ }^{42}$ Palm oil is consumed widely in low and middle income countries. It is high in saturated fat and causes a large increase in cholesterol concentrations. Empirical data from Mauritius show a reduction of $1 \mathrm{mmol} / \mathrm{L}$ in cholesterol concentrations through substitution of palm oil with soya oil. ${ }^{43}$ This reduction in cholesterol and low density lipoprotein cholesterol would equate to a $22 \%$ lower risk for cardiovascular disease, a huge effect by any standards. ${ }^{44}$
Strengthening of health system capacity to deliver care for non-communicable diseases

Strengthening of health systems and a well designed quality of care improvement framework are essential for concerted efforts to manage hypertension and diabetes for prevention of cardiovascular disease and chronic kidney disease. Shifting management of chronic diseases and risk factors from doctors to community healthcare workers holds promise and is being tested in rural areas in South Asia. ${ }^{34}$ Studies from Pakistan and India have shown that involving trained health workers in home health education on diet and physical activity and training general practitioners led to earlier diagnosis and better management of patients with hypertension or diabetes, and it was also cost effective. ${ }^{45-47}$ Scaling up similar models is likely to offer substantial reductions in cardiovascular disease and chronic kidney disease in the medium to long term.

Screening populations at high risk (such as people who are sedentary, overweight, or smokers; those with hypertension; those with a family history of diabetes or premature cardiovascular disease in first degree relatives; and women with a history of gestational diabetes) is essential for early diagnosis. Low cost strategies such as validated simple screening questionnaires, blood pressure measurement, and, if possible, fasting or random blood glucose 
measurement, urinary dipstick for protein, and non-fasting cholesterol measurement, may be used. Although the cost effectiveness of opportunistic screening compared with universal screening is likely to vary according to the characteristics of the population, its value cannot be overstated for countries with a high prevalence of diabetes. ${ }^{48}$

Making antihypertensives, statins, and diabetes drugs available for free or at low cost in primary healthcare centres should be prioritised. This is consistent with achievement of universal health coverage, including access to quality and affordable essential medicines for all, as advocated in the United Nations' sustainable development goals. ${ }^{49}$ High quality generic drugs produced in the region can help to make this sustainable. Fixed dose drug combinations may improve coverage and long term adherence in people with established disease, but their widespread use in primary prevention is still debated. ${ }^{50}$ Health insurance reforms must provide for screening and primary care for these conditions to reduce out of pocket expenditure. ${ }^{51}$

Evidence is growing for $\mathrm{m}$-health (mobile health technologies) interventions in improving adherence to treatment, maintaining appointments, data collection, and supporting health workers. ${ }^{52}$ More than $80 \%$ of the population of South Asia have mobile phones, and a large majority of villages are connected with mobile technology. ${ }^{53}$ This platform should be strongly considered in risk communication strategies and integration of care delivery for non-communicable diseases where feasible.

Public-private partnerships for non-communicable disease care should be encouraged to provide for unmet needs. Setting standards for long term public sector engagement; having transparent goals, inputs, and expectations; good governance of costs and fair allocation of profits; a shared vision and trust; and agreed processes for negotiation on common interests of partners are crucial to their success. The Sindh Institute of Urology and Transplantation in Karachi, Pakistan, providing dialysis services, and Aravind Eye Care System in India are good examples of successful public-private partnerships in the region. ${ }^{5455}$

\section{Consideration of population based} strategies to promote a healthy lifestyle Community based interventions to promote a healthy diet and physical activity and reduce smoking and stress will go a long way in delaying the onset of these diseases. The Indian Diabetes Prevention Program, and more recently the D-CLIP study, showed the effectiveness of lifestyle intervention in reducing the development of diabetes in people at high risk, while concurrently tackling problems with community acceptability and long term sustainability. ${ }^{5657}$

School health programmes, encouraged by WHO to inform children about risk factors for non-communicable diseases and promote physical activity, have been hindered by low education budgets and poor infrastructure. There are no restrictions on advertising unhealthy food to minors. ${ }^{58}$ Such legislation must be complemented with multi-sectoral action including involvement of schools and workplaces to influence diet and physical activity.

\section{Investment in surveillance and research}

Surveillance and monitoring are critical to raise awareness and inform policy and implementation. Although the WHO STEPS instrument (www.who.int/chp/steps/instrument/en/) for collecting data on risk factors for non-communicable diseases has been used in community based studies in South Asia, national implementation is lacking. ${ }^{59}$ All South Asian countries must institutionalise risk factor surveillance and establish robust cardiovascular disease, diabetes, and chronic kidney disease registries to track trends and monitor progress. Surveillance data must be shared publicly to create awareness.

Evidence on effective interventions to prevent and control non-communicable diseases in the region is very limited. The effect of school, workplace, and community based interventions must be evaluated. Research comparing single versus multiple risk factor screening, as well as opportunistic and targeted screening versus universal screening in all adults, will help to tailor screening strategies. Policy initiatives such as taxes and diet substitution must be rigorously evaluated for their feasibility and impact at a population level.

\section{Conclusion}

Capacity building, financing, and a strong quality assurance framework are crucial for the effectiveness, scalability, and long term sustainability of initiatives to curb non-communicable diseases in the South Asia region.

Contributors: AM and THJ drafted an outline for the concept note and the full paper. All co-authors contributed in an interactive process to the various sections of the drafts and approved the final version. Competing interests: We have read and understood BMJ policy on declaration of interests and have no relevant interests to declare.

Provenance and peer review: Commissioned; externally peer reviewed.

Anoop Misra, professor ${ }^{1,2}$

Nikhil Tandon, professor $^{3}$

Shah Ebrahim, honorary professor ${ }^{4}$

Naveed Sattar, professor ${ }^{5}$

Dewan Alam, visiting professor ${ }^{6}$
Usha Shrivastava, head of public health ${ }^{2}$

K M Venkat Narayan, professor

Tazeen H Jafar, professor $8,9,10$

${ }^{1}$ Fortis C-DOC Centre of Excellence for Diabetes, Metabolic Diseases and Endocrinology, New Delhi, India

${ }^{2}$ National Diabetes, Obesity and Cholesterol Foundation, India, and Diabetes Foundation (India)

${ }^{3}$ Department of Endocrinology, All India Institute of Medical Sciences, New Delhi, India

${ }^{4}$ Department of Non-Communicable Diseases Epidemiology, London School of Hygiene and Tropical Medicine, London, UK

5 Institute of Cardiovascular and Medical Sciences, University of Glasgow, UK

${ }^{6}$ School of Kinesiology and Health Science, Faculty of Health, York University, Toronto, ON, Canada

${ }^{7}$ Rollins School of Public Health, Emory University, Atlanta, GA, USA

${ }^{8}$ Program in Health Services and Systems Research, Duke-NUS Medical School, Singapore

${ }^{9}$ Department of Medicine, Aga Khan University, Karachi, Pakistan

${ }^{10}$ Duke Global Health Institute, Durham, Duke University, NC, USA

Correspondence to: TH Jafar tazeen.jafar@duke-nus.edu.sg

Tillin T, Hughes AD, Mayet J, et al. The relationship cardiovascular disease in Europeans, South Asians, and African Caribbeans: SABRE (Southall and Brent Revisited) -- a prospective population-based study. J Am Coll Cardiol 2013;61:1777-86. doi:10.1016/j. jacc. 2012.12.046

2 Sattar N, Gill JM. Type 2 diabetes in migrant south Asians: mechanisms, mitigation, and management. Lancet Diabetes Endocrinol 2015;3:1004-16. doi:10.1016/S2213-8587(15)00326-5.

3. World Bank. World development indicators. 2015 http://databank.worldbank.org/data/reports. aspx?source=health-nutrition-and-populationstatistics.

4 World Health Organization. Health statistics and information systems. 2015. http://www.who.int/ healthinfo/indicators/2015/metadata/en/.

5 Institute for Health Metrics and Evaluation. GBD Compare. 2013. http://vizhub.healthdata.org/ gbd-compare.

6 GBD 2015 Mortality and Causes of Death Collaborators. Global, regional, and national life expectancy, all-cause mortality, and cause-specific mortality for 249 causes of death, 1980-2015: systematic analysis for the Global Burden of Disease Study 2015. Lancet 2016;388:1459-544. doi:10.1016/ S0140-6736(16)31012-1.

7 Moran AE, Tzong KY, Forouzanfar MH, et al. Variations in ischemic heart disease burden by age, country, and income: the Global Burden of Diseases, Injuries, and Risk Factors 2010 study. Glob Heart 2014;9:91-9. doi:10.1016/j.gheart.2013.12.007.

8 Yusuf S, Hawken S, Ounpuu S, et al. INTERHEART Study Investigators. Effect of potentially modifiable risk factors associated with myocardial infarction in 52 countries (the INTERHEART study): case-control study. Lancet 2004:364:937-52. doi:10.1016/ S0140-6736(04)17018-9.

9 Modi GK, Jha V. The incidence of end-stage renal disease in India: a population-based study. Kidney Int 2006;70:2131-3. doi:10.1038/sj.ki.5001958.

10 Dare AJ, Fu SH, Patra J, Rodriguez PS, Thakur JS, Jha P. Million Death Study Collaborators. Renal failure deaths and their risk factors in India 2001-13: nationally representative estimates from the Million Death Study. Lancet Glob Health 2017;5:e89-95. doi:10.1016/ S2214-109X(16)30308-4.

11 Pandian JD, Sudhan P. Stroke epidemiology and stroke care services in India. J Stroke 2013;15:128-34. doi:10.5853/jos.2013.15.3.128.

12 Ng M, Freeman MK, Fleming TD, et al. Smoking prevalence and cigarette consumption in 187 countries, 1980-2012. JAMA 2014;311:183-92. doi:10.1001/jama.2013.284692. 
13 Jha P, Khan J, Mishra S, Gupta P. Raising taxes key to accelerate tobacco control in South Asia. BM] 2017;357:j1176.

14 O’Donnell MJ, Chin SL, Rangarajan S, et al. INTERSTROKE investigators. Global and regional effects of potentially modifiable risk factors associated with acute stroke in 32 countries (INTERSTROKE): a case-control study. Lancet 2016;388:761-75. doi:10.1016/S0140-6736(16)30506-2.

15 Farzadfar F, Finucane MM, Danaei G, et al. Global Burden of Metabolic Risk Factors of Chronic Diseases Collaborating Group (Cholesterol). National, regional, and global trends in serum total cholesterol since 1980: systematic analysis of health examination surveys and epidemiological studies with 321 country-years and 3.0 million participants. Lancet 2011;377:578-86. doi:10.1016/S0140-6736(10)62038-7.

16 NCD Risk Factor Collaboration (NCD-RisC). Worldwide trends in diabetes since 1980: a pooled analysis of 75 population-based studies with 4.4 million participants. Lancet 2016;387:1513-30. doi:10.1016/

S0140-6736(16)00618-8.

17 NCD Risk Factor Collaboration (NCD-RisC). Worldwide trends in blood pressure from 1975 to 2015: a pooled analysis of 1479 population-based measurement studies with 19.1 million participants. Lancet 2017;389:37-55. doi:10.1016/ S0140-6736(16)31919-5.

18 Whincup PH, Nightingale CM, Owen CG, et al. Early emergence of ethnic differences in type 2 diabetes precursors in the UK: the Child Heart and Health Study in England (CHASE Study). PLoS Med 2010;7:e1000263. doi:10.1371/journal.pmed.1000263.

19 Jafar TH, Islam M, Poulter N, et al. Children in South Asia have higher body mass-adjusted blood pressure levels than white children in the United States: a comparative study. Circulation 2005;111:1291-7. doi:10.1161/01.CIR.0000157699.87728.F1.

20 Bhargava SK, Sachdev HS, Fall CH, et al. Relation of serial changes in childhood body-mass index to impaired glucose tolerance in young adulthood. N Engl J Med 2004;350:865-75. doi:10.1056/NEJMoa035698.

21 Misra A, Anoop S, Gulati S, Mani K, Bhatt SP, Pandey RM. Body fat patterning, hepatic fat and pancreatic volume of non-obese Asian Indians with type 2 diabetes in North India: a case-control study. PLoS One 2015;10:e0140447. doi:10.1371/journal. pone. 0140447.

22 Peters MJ, Ghouri N, McKeigue P, Forouhi NG, Sattar N. Circulating IL-6 concentrations and associated anthropometric and metabolic parameters in South Asian men and women in comparison to European whites. Cytokine 2013;61:29-32. doi:10.1016/i.cyto.2012.09.002.

23 Gupta R, Kaur M, Islam S, et al. Association of household wealth index, educational status, and socia capital with hypertension awareness, treatment, and control in South Asia. Am J Hypertens 2017; hpw169. doi:10.1093/ajh/hpw169.

24 Jafar TH, Haaland BA, Rahman A, et al. Noncommunicable diseases and injuries in Pakistan: strategic priorities. Lancet 2013;381:2281-90. doi:10.1016/S0140-6736(13)60646-7.

25 Karmacharya BM, Koju RP, LoGerfo JP, et al. Awareness, treatment and control of hypertension in Nepal: findings from the Dhulikhel Heart Study. Heart Asia 2017;9:1-8. doi:10.1136/heartasia-2016-010766.

26 Joshi SR, Das AK, Vijay VJ, Mohan V. Challenges in diabetes care in India: sheer numbers, lack of awareness and inadequate control. J Assoc Physicians India 2008;56:443-50.

27 Rahman MS, Akter S, Abe SK, et al. Awareness, treatment, and control of diabetes in Bangladesh: a nationwide population-based study. PLoS One 2015;10:e0118365. doi:10.1371/journal.pone.0118365.

28 Jessani S, Bux R, Jafar TH. Prevalence, determinants, and management of chronic kidney disease in Karachi, Pakistan - a community based cross-sectional study. BMC Nephrol 2014;15:90. doi:10.1186/1471-2369-15-90.
29 Zaidi SA, Prasad BG, Mathur KK. A socio-medical study of male industrial workers along with their families covered under the employees' state insurance scheme in Aishbagh, Lucknow. Indian J Med Sci 1970;24:272-84

30 Jooma R, Jalal S. Designing the first ever health insurance for the poor in Pakistan--a pilot project. J Pak Med Assoc 2012:62:56-8.

31 Prabhakaran D, Jeemon P, Roy A. Cardiovascular diseases in India: current epidemiology and future directions. Circulation 2016;133:1605-20. doi:10.1161/CIRCULATIONAHA.114.008729.

32 Jafar TH, Jessani S, Jafary FH, et al. General practitioners' approach to hypertension in urban Pakistan: disturbing trends in practice. Circulation 2005;111:1278-83. doi:10.1161/01. CIR.0000157698.78949.D7.

33 Mendis S, Abegunde D, Yusuf S, et al. WHO study on Prevention of REcurrences of Myocardial Infarction an StrokE (WHO-PREMISE). Bull World Health Organ 2005;83:820-9.

34 Jafar TH, Silva Ad, Naheed A, et al. COBRA-BPS Study Group. Control of blood pressure and risk attenuation: a public health intervention in rural Bangladesh, Pakistan, and Sri Lanka: feasibility trial results. Hypertens 2016;34:1872-81. doi:10.1097/ H.H.0000000000001014.

35 Huffman MD, Prabhakaran D, Abraham AK, Krishnan MN, Nambiar AC, Mohanan PP. Kerala Acute Coronary Syndrome Registry Investigators. Optimal in-hospital and discharge medical therapy in acute coronary syndromes in Kerala: results from the Kerala acute coronary syndrome registry. Circ Cardiovasc Qual Outcomes 2013;6:436-43. doi:10.1161/ CIRCOUTCOMES.113.000189.

36 World Bank. Health expenditure per capita: South Asia. 2014. http://data.worldbank.org/indicator/SH.XPD. PCAP.PP.KD.

37 Rajapakshe W, Isaakidis P, Sagili KD, et al. Screening patients with tuberculosis for diabetes mellitus in Ampara, Sri Lanka. Public Health Action 2015;5:150-2 doi:10.5588/pha.15.0006

38 Nishtar S, Faruqui AM, Mattu MA, Mohamud KB, Ahmed A. The National Action Plan for the Prevention and Control of Non-communicable Diseases and Health Promotion in Pakistan--Cardiovascular diseases. J Pak Med Assoc 2004;54(Suppl 3):S14-25.

39 Basu S, Vellakkal S, Agrawal S, Stuckler D, Popkin B, Ebrahim S. Averting obesity and type 2 diabetes in India through sugar-sweetened beverage taxation: an economic-epidemiologic modeling study. PLoS Med 2014;11:e1001582. doi:10.1371/journal. pmed.1001582.

40 Colchero MA, Popkin BM, Rivera JA, Ng SW. Beverage purchases from stores in Mexico under the excise tax on sugar sweetened beverages: observational study. BMJ 2016;352:h6704. doi:10.1136/bmj.h6704.

41 Nair CG. Kerala budget imposes 'fat tax' on pizzas, burgers. 2016. http://www.thehindu.com/news/ national/kerala/Kerala-budget-imposes\%E2\%80\%98fat-tax\%E2\%80\%99-on-pizzas-burgers article14477934.ece.

42 Basu S, Babiarz KS, Ebrahim S, Vellakkal S, Stuckler D, Goldhaber-Fiebert JD. Palm oil taxes and cardiovascular disease mortality in India: economicepidemiologic model. BMJ 2013;347:f6048. doi:10.1136/bmi.f6048

43 Uusitalo U, Feskens EJ, Tuomilehto J, et al. Fall in total cholesterol concentration over five years in association with changes in fatty acid composition of cooking oil in Mauritius: cross sectional survey. BM/ 1996;313:1044 6. doi:10.1136/bmj.313.7064.1044.

44 Baigent C, Blackwell L, Emberson J, et al. Cholesterol Treatment Trialists' (CTT) Collaboration. Efficacy and safety of more intensive lowering of LDL cholesterol: a meta-analysis of data from 170,000 participants in 26 randomised trials. Lancet 2010;376:1670-81. doi:10.1016/S0140-6736(10)61350-5.
45 Jafar TH, Hatcher J, Poulter N, et al. Hypertension Research Group. Community-based interventions to promote blood pressure control in a developing country: a cluster randomized trial. Ann Intern Med 2009;151:593-601. doi:10.7326/0003-4819-151-9-200911030-00004

46 Ali MK, Singh K, Kondal D, et al. CARRS Trial Group. Effectiveness of a multicomponent quality improvement strategy to improve achievement of diabetes care goals: a randomized, controlled trial. Ann Intern Med 2016;165:399-408

47 Jafar TH, Allen IC, Jehan I, et al. Health education and general practitioner training in hypertension management: long-term effects on kidney function. Clin J Am Soc Nephrol 2016;11:1044-53. doi:10.2215/ CJN.05300515.

48 Narayan KM, Lall D. Screening for type 2 diabetes: does the ADDITION--Cambridge trial distract from the real policy challenge? Natl Med I India 2013;26:1-3.

49 United Nations. Sustainable development goals. Goal 3: Ensure healthy lives and promote well-being for all at all ages. http://www.un.org/ sustainabledevelopment/health/

50 Thom S, Poulter N, Field J, et al. UMPIRE Collaborative Group. Effects of a fixed-dose combination strategy on adherence and risk factors in patients with or at high risk of CVD: the UMPIRE randomized clinical trial. JAMA 2013;310:918-29. doi:10.1001/jama.2013.277064.

51 Lagomarsino G, Garabrant A, Adyas A, Muga R, Otoo N. Moving towards universal health coverage: health insurance reforms in nine developing countries in Africa and Asia. Lancet 2012;380:933-43. doi:10.1016 S0140-6736(12)61147-7.

52 Hall CS, Fottrell E, Wilkinson S, Byass P. Assessing the impact of mHealth interventions in low- and middle-income countries--what has been shown to work? Glob Health Action 2014;7:25606. doi:10.3402/ gha.v7.25606

53 World Bank. Mobile cellular subscriptions (per 100 people). 2016. http://data.worldbank.org/indicator/ IT.CEL.SETS.P2.

54 Morad Z, Choong HL, Tungsanga K, Suhardjono Funding renal replacement therapy in southeast Asia: building public-private partnerships in Singapore, Malaysia, Thailand, and Indonesia. Am / Kidney Dis 2015;65:799-805. doi:10.1053/j.ajkd.2014.09.031.

55 Rosenberg T. A hospital network with a vision. 2013. https://opinionator.blogs.nytimes.com/2013/01/16/ in-india-leading-a-hospital-franchise-with-vision/? $r=0$

56 Ramachandran A, Snehalatha C, Mary S, Mukesh B, Bhaskar AD, Vijay V. Indian Diabetes Prevention Programme (IDPP). The Indian Diabetes Prevention Programme shows that lifestyle modification and metformin prevent type 2 diabetes in Asian Indian subjects with impaired glucose tolerance (IDPP-1) Diabetologia 2006;49:289-97. doi:10.1007/ s00125-005-0097-z.

57 Weber MB, Ranjani H, Staimez LR, et al. The stepwise approach to diabetes prevention: results from the D-CLIP randomized controlled trial. Diabetes Care 2016;39:1760-7. doi:10.2337/dc16-1241.

58 Boyland EJ, Nolan S, Kelly B, et al. Advertising as a cue to consume: a systematic review and meta-analysis of the effects of acute exposure to unhealthy food and nonalcoholic beverage advertising on intake in children and adults. Am / Clin Nutr 2016;103:519-33. doi:10.3945/ajcn.115.120022.

59 Razzaque A, Nahar L, Yunus M, Karar Zunaid A, Mohammad Shafiqul I, Yunus M. Sociodemographic differentials of selected noncommunicable diseases risk factors among adults in Matlab, Bangladesh: findings from a WHO STEPS survey. Asia Pac J Public Health 2011:23:183-91 doi:10.1177/1010539510392743.

Cite this as: $B M / 2017 ; 357: j 1420$ http://dx.doi.org/10.1136/bmj.j1420 